\title{
U.S. Competitiveness Addressed at Washington Forum
}

The 1990 Washington Forum of The Minerals, Metals, and Materials Society (TMS), "Advanced Materials for the Nineties," had U.S. competitiveness as its central theme. Held in Washington, DC on May 3, the one-day conference attracted about 40 participants and featured five presentations as well as a lunchtime address by Congressman Don Ritter (R-PA).

Martin Marietta Corporation's John Greene, director of materials manufacturing R\&D, described his company's "strategic partners" approach to transferring technology within its corporate structure. He explained the importance of searching out strategic industrial partners to fill specific roles in the business and manufacturing aspects of scaling up from $R \& D$. Greene described two cases where external manufacturers helped transfer R\&D results to the manufacturing arms of the corporation. One involved an advanced metal-matrix composite based on in situ precipitation, the other an alloy of weldable high-strength aluminum-lithium called Weldalite ${ }^{\mathrm{m}}$.

The criteria for a successful process, said Greene, include a vital interest on the part of both parties in such an arrangement, a protected technology situation in which patents and possibly exclusive market positions can be offered to a partner, good chemistry between the technical and business management teams of the corporations involved, the possibility of dual-use applications for the technology so that a market in addition to defense is clear, and a highly entrepreneurial, aggressive program manager to pursue the project. Greene said that in the best of circumstances the time between a device's first reduction to practice and its reaching the marketplace can be drastically shortened.

Lyle Schwartz from the National Institute of Standards and Technology (NIST) described programs available, particularly through NIST, for interaction between government R\&D laboratories and industry. Today, technology transfer means more than offering products off the shelf which have already been developed as part of a government mission, he said. Rather, the most effective tech transfer is through joint and early collaboration with industry at the R\&D stage. Schwartz cited the need to provide a risk reduction mechanism for industry and the need to bridge a distinct, still existing barrier between materials sci- ence and materials engineering.

Schwartz also described the Advanced Technology Program, which is expected to be a growing effort headed by NIST to create industry-led consortia throughout the United States. He concluded by detailing an expert system developed by NIST to control a metal atomization process that produces rapidly solidified metal alloy powder. The program, he said, is representative of the type in which government can participate with the aim of transferring the results to industry.

Sig Hecker, director of the Los Alamos National Laboratory, described the current situation regarding technology transfer from Department of Energy national laboratories to industry. Hecker noted that recent tech-transfer-related legislation and cooperative $R \& D$ agreements are becoming tools to mate national laboratories with industry. He listed several strategic technologies in which they are appropriate, including supercomputers, laser technology, energy technology, environmental control technology, superconductors, biotechnology, materials synthesis and processing, and semiconductors. He pointed to some commercially relevant advances that came from Los Alamos, including the use of free-electron lasers for XUV lithography at less than 0.1 micron feature sizes.

Hecker extensively described the Superconductivity Pilot Centers, launched by DOE as an experiment two years ago and based at Los Alamos, Oak Ridge, and Argonne National Laboratories. He said that the tech transfer mechanisms employed by the Pilot Centers have worked very well and are now being copied in the more recent initiatives.

Gordon Geiger of the Cargill Corporation followed with an assessment of the U.S. educational situation in engineering. By and large, students at the undergraduate level are not receiving any practical engineering education relevant to processing unless they come out of such disciplines as chemical engineering, he said. Students are therefore not prepared to handle the full spectrum of materials science and engineering in graduate school. Practical and empirical experience in processing is necessary, continued Geiger. He recommended a strong new emphasis on engineering research in the form of texts, government grants, and a return to the acceptability of teaching the empirical proc- ess engineering aspects of the field.

During his lunchtime address, Rep. Don Ritter applauded the United States for striving to be at the "cutting edge" of technology, but criticized it for ignoring, for the most part, the "rest of the blade." As economic power replaces military power as the key force in the global community, said Ritter, the United States faces formidable competition from the European Economic Community, Japan, and elsewhere in Asia in the development of products for the marketplace. "Too often we have won the battle for the Nobel prizes but lost the war of creating highly sophisticated manufacturing jobs, profits and wealth," he said.

Ritter identified four areas that need to be addressed: (1) the present barriers in high technology that prevent companies from converting basic knowledge into products; (2) the failure of government to recognize and "bet on" the industries and technologies most important to the country's overall economic power; (3) the need to raise the awareness of the underlying critical role of materials R\&D in many federally funded projects, which could aid Congress in setting national priorities; and (4) the need for a "quality revolution" in the U.S. educational system to prepare students for careers in science and engineering.

Carolyn Hansen, currently a consultant for the Canadian government, addressed the human side of the technology transfer equation, describing the difficulties and some possible solutions to creating linkages between institutions, particularly across international boundaries. The challenges, in order of increasing difficulty, said Hansen, are the need to define the subject matter, find appropriate partners, find financing, and develop a consensus for dividing the spoils. The difficulties arise through the distances between parties, cultural differences, bureaucracies, and the like. She emphasized the need to have contacts through individuals and to have a great deal of patience and understanding for the approaches taken by different cultures. An appreciation for the nontechnical difficulties of communication such as language barriers, which can be linchpins in developing good relationships for interorganizational and international cooperation, is essential, she concluded. 